\title{
Relative bioavailability of soil-bound polychlorinated biphenyls in lactating goats
}

\author{
Cyril Feidt, ${ }^{1}$ Fayçal Ounnas, ${ }^{1}$ Diane Julien-David, Stefan Jurjanz, Hervé Toussaint, \\ Catherine Jondreville, and Guido Rychen ${ }^{2}$ \\ Université de Lorraine, INRA, UR AFPA, 2 avenue de la Forêt de Haye B.P. 172, F-54505 Vandœuvre-lès-Nancy, France
}

\begin{abstract}
Livestock may be exposed to organic pollutants via ingestion of contaminated matrices such as fodder or soil. The question on contribution of soil-bound polychlorinated biphenyls (PCB) to livestock exposure was not yet considered. The aim of this study was to assess the relative bioavailability of soil-bound $\mathrm{PCB}$ by assessing milk excretion of indicator PCB (I-PCB) after ingestion by goats of graded levels of PCB (mainly PCB forms 153, 180, and 138) in soil-contaminated feeds or in oil-contaminated feeds. Eight multiparous Alpine goats were grouped in 4 pairs on the basis of body weight and milk yield. In each pair, one goat was assigned to the soil feeds and the other one to the oil feeds. The experiment consisted of a 7-d adaptation period, followed by a 96-d exposure period. The exposure period was divided into 3 successive 32 -d periods during which each goat received either 3 soil feeds or 3 oil feeds, distributed in increasing rank of contamination. During the last week of each 32-d period, milk from each goat was collected during 3 successive 24 -h periods, stored at $-20^{\circ} \mathrm{C}$, and freeze dried before analysis (extraction by accelerated solvent extraction, followed by gas chromatography-mass spectrometry analysis). Bioavailability of I-PCB from soil or spiked oil feeds was estimated by means of the slope-ratio method from I-PCB concentration in milk in response to ingested I-PCB. Relative bioavailability was found to vary from 36 to $50 \%$ for PCB 118, 138, and 153 and it was $73 \%$ for PCB 180. When considered globally, the response obtained with the I-PCB was estimated to $51 \%$. Relative bioavailability was not established for PCB 52 and 101, compounds known to be readily cleared and showing low concentrations in milk. For PCB 28, no significant interaction was found between matrix and dose. This experiment reveals that PCB bound to soil are potentially liberated from soil during the digestive
\end{abstract}

Received October 29, 2012.

Accepted February 10, 2013.

${ }^{1}$ These authors contributed equally to the work.

${ }^{2}$ Corresponding author: guido.rychen@ensaia.inpl-nancy.fr process and may undergo absorption, distribution, metabolism, and excretion. Thus, soil has to be considered as a risk matrix for ruminants and rearing practices in contaminated areas should strictly reduce the risk of soil ingestion by the ruminants.

Key words: polychlorinated biphenyl, soil, ruminant, milk

\section{INTRODUCTION}

Livestock may be exposed to organic pollutants via ingestion of contaminated matrices such as fodder or soil (McLachlan et al., 1990; Fries, 1995; Mamontova et al., 2007). Depending on the bioavailability of the pollutants, this exposition may lead to the contamination of animal products. Contaminated milk products are considered as the main contributors to human exposure to persistent organic pollutants, widely recognized as environmental and food contaminants (Focant et al., 2002; Darnerud et al., 2006). Polychlorinated biphenyls (PCB) belong to the persistent organic pollutant group. They mainly originate from anthropogenic activity, and their ubiquitous presence in the environment causes concerns due to their persistence and potential bioaccumulation in the environment, and also in animals and human tissues (Matscheko et al., 2002). Indeed, the carryover rates of PCB from fodder to milk have been shown to be higher than $50 \%$ (Costera et al., 2006; Ounnas et al., 2010).

Until recently, livestock exposure to PCB via involuntary ingestion of contaminated soil has not been evaluated. However, it is known that grazing dairy cows may involuntary ingest non-negligible amounts of soil. Jurjanz et al. (2012) demonstrated that, in bad grazing conditions, dairy cows may ingest up to $1.5 \mathrm{~kg}$ of soil per day (i.e., $10 \%$ of the total daily DMI). It is also known that in accidentally contaminated areas, PCB contamination in agricultural soils may reach $50 \mathrm{ng} / \mathrm{g}$ (Rychen et al., 2008). Thus, the question on soil-bound PCB bioavailability appears of importance when assessing the exposure of cattle to PCB, and indirectly when assessing the exposure of humans through animal products. It has been suggested that PCB have a high 
affinity for OM (Kookana, 2011) and, therefore, would show limited bioavailability in soils ( $\mathrm{Pu}$ et al., 2006). No information is currently available on the way the gastrointestinal digestion process of ruminants would affect this physical/biochemical link between pollutants and the soil constituents.

The aim of this study was to assess the relative bioavailability (RB) of soil-bound PCB by assessing milk excretion of indicator PCB (I-PCB) after ingestion by goats of graded levels of PCB in contaminated soil feeds or in contaminated oil feeds. The spiked-oil feeds were considered as the reference material. A similar approach with the same PCB-contaminated soil was performed recently in laying hens (Fournier et al., 2012). Those authors observed that RB in eggs was identical for soil and oil, suggesting that the soil constituents do not retain the $\mathrm{PCB}$ during the digestive process in poultry. A follow-up problem arising from their study is to characterize the ability of lactating ruminants to extract PCB during the digestive process. In a previous study, Ounnas et al. (2009) showed that in the lactating goat, the RB of soil-bound polycyclic aromatic hydrocarbons depended on the compound.

\section{MATERIALS AND METHODS}

\section{Contaminated Matrices and Experimental Feeds}

Collection of PCB-Contaminated Soil. Twelve kilograms of contaminated surface soil were collected from superficial horizons (O and A) 3 mo after an accidental fire (fire of stock of wood; Saint-Cyprien, France). After drying for $20 \mathrm{~d}$ at room temperature $\left(18-20^{\circ} \mathrm{C}\right)$, the soil was manually ground, sieved at 2 $\mathrm{mm}$, homogenized, and stored in closed glass containers at $-20^{\circ} \mathrm{C}$. The physical and chemical properties of the soil were determined ( $0.7 \%$ organic carbon, $82.6 \%$ sand, $6.3 \%$ clay, and $11.1 \%$ silt). Analyses performed on this accidentally PCB-contaminated soil revealed that the I-PCB profile was clearly dominated by the mostchlorinated and -lipophilic congeners [PCB 153 (30\%), PCB 180 (25\%), and PCB 138 (22\%)].

Production of PCB-Spiked Oil. Oil was chosen as the reference material as recommended by Kawamaru et al. (1988). Sunflower oil (Buttella; Cargill Oil Packers France SAS, Château-Gontier, France) constituted the spiked reference matrix to be studied. To achieve the same profile of I-PCB in spiked oil and in soil, the mixture of $\mathrm{PCB}$ incorporated in oil was extracted from soil. Extraction was performed by accelerated solvent extraction (ASE; ASE 300 solvent extractor; Dionex Corp., Sunnyvale, CA) using a mixture of toluene and acetone $(70: 30, \mathrm{vol} / \mathrm{vol})$. Solvents were evaporated from extracts by drying at $40^{\circ} \mathrm{C}$ under vacuum. Diluted in toluene, the extract was analyzed for I-PCB concentration. At this step, the extract was enriched with PCB 138 (Oekanal, 99\% purity; catalog no. 35494; SigmaAldrich, St. Louis, MO), PCB 153 (Oekanal, 99\% purity; catalog no. 35602; Sigma-Aldrich), and PCB 180 (Oekanal, 99\% purity; catalog no. 35495; SigmaAldrich) to obtain the same PCB profile as in soil. This enriched extract was introduced in oil. Oil was spiked so that $15 \mathrm{~g}$ of oil delivered the same dose of I-PCB as $40 \mathrm{~g}$ of soil. Spiked oil was heated at $40^{\circ} \mathrm{C}$ under vacuum to evaporate toluene and stored in tinted glass flasks at $4^{\circ} \mathrm{C}$ before being incorporated in the feeds.

Preparation of the Experimental Feeds. Six experimental feeds were formulated on the basis of a lactating goat basal feed to meet the nutritional requirements of the lactating animals (INRA, 2007). Forty grams of sand and $15 \mathrm{~g}$ of blank oil were introduced per kilogram (Table 1). Three soil feeds were manufactured by replacing $13.3 \mathrm{~g}$ (treatment 1), $26.7 \mathrm{~g}$ (treatment 2), or $40 \mathrm{~g}$ (treatment 3) of sand by contaminated soil. Similarly, 3 oil feeds were formulated by replacing $5 \mathrm{~g}$ (treatment 4), $10 \mathrm{~g}$ (treatment 5), or $15 \mathrm{~g}$ (treatment 6) of blank oil by spiked oil. All experimental feeds were pelleted $(3 \mathrm{~mm})$ at the Institut National de la Recherche Agronomique (INRA) facilities [Unité de Recherche Associée (URA), Tours, Nouzilly, France]. Feed DM concentration was $86 \pm 1 \%$.

\section{Animals}

Eight multiparous Alpine goats (69.4-kg BW, second and third lactations, and second month postpartum) from the Domaine Experimental de la Bouzule (Champenoux, France) were used. The animal protocol was in accordance with the general directive No. 1986/609/ CEE on animal care. The animals were allowed an adaptation period of $1 \mathrm{wk}$ within individual pens under natural light conditions. During the experimental period, the goats received every day $1,000 \mathrm{~g}$ of the contaminated feed, 2,000 g of a commercial compound feed, and had ad libitum access to hay, water, and mineral feed. Throughout the experiment the animals were mechanically milked twice per day and the volumes of daily produced milk were individually recorded.

\section{Experimental Design}

The 8 goats were grouped in 4 pairs on the basis of BW and milk yield and placed in individual pens. In each pair, one goat was assigned to the soil feeds and the other one to the oil feeds. The experiment consisted in a 7-d adaptation period, followed by a 96 -d exposure period. During the adaptation period, goats received $3,000 \mathrm{~g}$ of a commercial compound feed. During the 
Table 1. Composition and contamination level of the experimental feeds

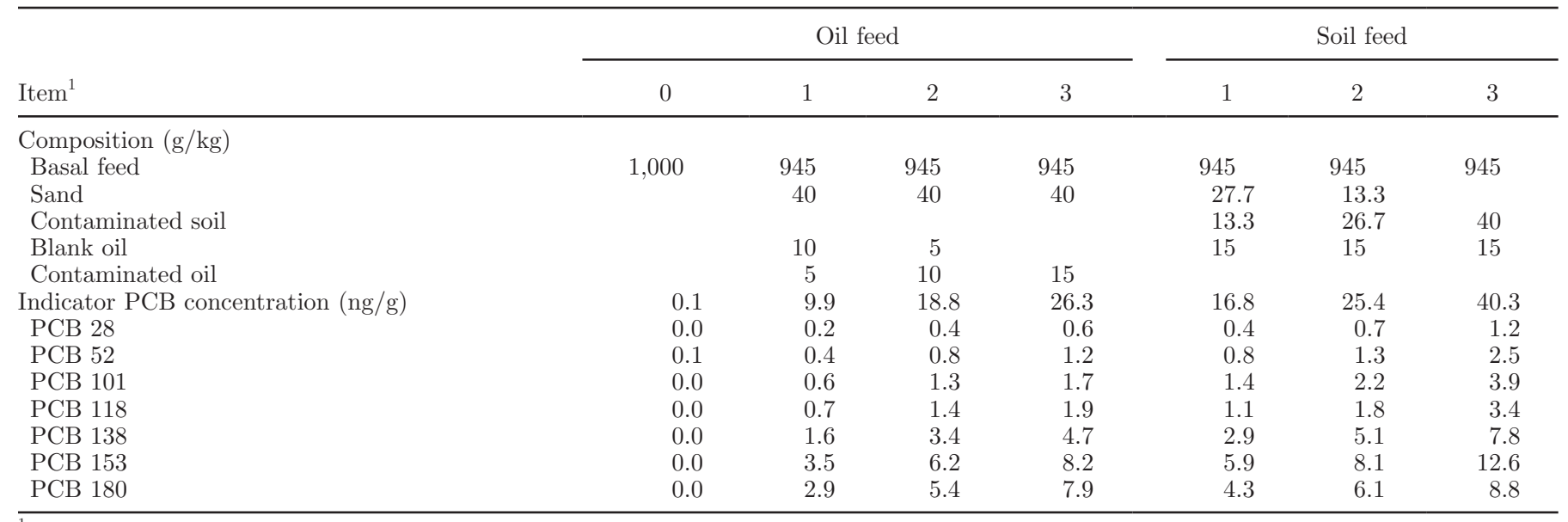

${ }^{1} \mathrm{PCB}=$ polychlorinated biphenyl.

subsequent 96-d exposure period, 1,000 g of the commercial compound feed was replaced by $1,000 \mathrm{~g}$ of 1 of the 6 experimental feeds. The exposure period was divided into 3 successive 32 -d periods during which each goat received either the 3 soil feeds or the 3 oil feeds, successively distributed in increasing rank of contamination. During the last week of each 32-d period, milk from each goat was collected during 3 successive 24 -h periods, mixed, and stored at $-20^{\circ} \mathrm{C}$ and freeze dried before analysis. Control milk was collected from each goat during the last week of the adaptation period. The duration of exposure of $32 \mathrm{~d}$ for each treatment resulted from the studies of Costera et al. (2006) and Ounnas et al. (2010) who reported that the excretion of PCB in ruminant milk achieves a plateau after less than $3 \mathrm{wk}$ of exposure. Due to the high lipophilicity and low metabolization of I-PCB, milk fat was considered as a relevant matrix (target compartment) to assess bioavailability (Slob et al., 1995).

The quantities of contaminated and uncontaminated feeds were recorded daily for each goat. A sample of each feed was collected to determine the $\mathrm{DM}$ and $\mathrm{PCB}$ concentrations. The quantities of dry feed ingested were then calculated for each goat.

\section{Sample Analysis}

Internal 13C-labeled PCB standards (PCB 28/52/101/118/138/153/180; Cambridge Isotope Laboratories, Andover, MA) were added to each sample of milk and of feed. Polychlorinated biphenyls were extracted from the feed samples by ASE (ASE 300; Dionex Corp.), using mixed toluene (Pestanal; SigmaAldrich) and acetone (Pestanal; Sigma-Aldrich) at 70:30 (vol/vol) before purification.
For each milk sample, $2 \mathrm{~mL}$ of saturated dipotassium oxalate (Emsure; Merck KGaA, Darmstadt, Germany) was added to precipitate the proteins, followed by ethanol (for residue analysis; Sigma-Aldrich) and diethyl ether (for residue analysis; Sigma-Aldrich). The fat was extracted twice with $n$-pentane (Pestanal; SigmaAldrich). The extract was evaporated until dryness, permitting gravimetric determination of the fat content. Finally, $25 \mathrm{~mL}$ of cyclohexane (Pestanal; SigmaAldrich) was added before purification.

The samples were transferred into a column for purification (length: $50 \mathrm{~cm}$; i.d.: $2.5 \mathrm{~cm}$ ), containing successive layers, including $6 \mathrm{~g}$ of Florisil (Promochem, Molsheim, France) in $10 \mathrm{~mL}$ of cyclohexane, $5 \mathrm{~g}$ of anhydrous sodium sulfate (Emsure; Merck KGaA), 4 $\mathrm{g}$ of pure silica (Sigma-Aldrich), $8 \mathrm{~g}$ of silica acidified with concentrated sulfuric acid (22\%), $10 \mathrm{~g}$ of silica acidified with concentrated sulfuric acid (Merck KGaA; $44 \%$ ), and $5 \mathrm{~g}$ of anhydrous sodium sulfate. Indicator PCB were eluted with $80 \mathrm{~mL}$ of cyclohexane; eluates were evaporated until dry after spiking with external standard (13C-labeled PCB 111; Cambridge Isotope Laboratories) and reconstituted with $50 \mu \mathrm{L}$ of toluene.

The final determination of PCB was performed with an Agilent 5975C GC instrument coupled with an Agilent 7890A mass sensitive detector (Agilent Technologies Inc., Santa Clara, CA). Data acquisition, data processing, and instrumental control were performed by MSD ChemStation software E.02.00.493 (Agilent Technologies Inc.). Analytes were separated in DB5-ms Ultra Inert columns $(30 \mathrm{~m} \times 0.25 \mathrm{~mm} \times 0.25 \mu \mathrm{m} ; \mathrm{J} \& \mathrm{~W}$ Scientific Inc., Folsom, CA). The column temperature gradient was programmed as follows: $110^{\circ} \mathrm{C}$ (hold for $1 \mathrm{~min})$ to $200^{\circ} \mathrm{C}$ at $20^{\circ} \mathrm{C} / \mathrm{min}$, to $230^{\circ} \mathrm{C}$ at $2^{\circ} \mathrm{C} / \mathrm{min}$, to $270^{\circ} \mathrm{C}$ at $5^{\circ} \mathrm{C} / \mathrm{min}(0 \mathrm{~min})$, and finally to $300^{\circ} \mathrm{C}$ at 
Table 2. Parameters of the linear response of indicator polychlorinated biphenyl (PCB) concentration in milk (ng/g of fat) to the concentration of ingested indicator PCB ( $\mathrm{ng} / \mathrm{g}$ of feed) originating from contaminated soil or from contaminated oil

\begin{tabular}{|c|c|c|c|c|c|c|c|c|c|c|}
\hline \multirow{2}{*}{ Item } & \multicolumn{2}{|c|}{ Intercept } & \multicolumn{4}{|c|}{ PCB (ng/g of feed) } & \multirow{2}{*}{$P$-value } & \multirow{2}{*}{$\mathrm{RSD}^{1}$} & \multirow{2}{*}{$\mathrm{R}^{2}$} & \multirow{2}{*}{$\mathrm{RB}^{2}$} \\
\hline & Parameter & $P$-value & \multicolumn{2}{|c|}{ Soil feed } & \multicolumn{2}{|c|}{ Oil feed } & & & & \\
\hline PCB 28 & & NS & 4.8 & $<0.001$ & 6.4 & $<0.001$ & NS & 1.2 & 0.87 & \\
\hline PCB 52 & 2.2 & $<0.001$ & 0.19 & NS & 0.37 & NS & NS & 0.65 & 0.11 & \\
\hline PCB 101 & 0.78 & $<0.01$ & 0.29 & $<0.001$ & 0.50 & $<0.01$ & NS & 0.51 & 0.40 & \\
\hline PCB 153 & & NS & 3.1 & $<0.001$ & 6.1 & $<0.001$ & $<0.001$ & 5.4 & 0.80 & 0.50 \\
\hline PCB 180 & & NS & 4.0 & $<0.001$ & 5.4 & $<0.001$ & $<0.001$ & 4.1 & 0.94 & 0.73 \\
\hline $\begin{array}{l}\text { Indicator } \\
\text { PCB }\end{array}$ & & NS & 3.0 & $<0.001$ & 5.9 & $<0.001$ & $<0.001$ & 16 & 0.92 & 0.51 \\
\hline
\end{tabular}

${ }^{1}$ Residual standard deviation.

${ }^{2}$ Relative bioavailability of PCB present in soil, calculated as the ratio of the slope of the response fitted with soil to the slope of the response fitted with oil.

$10^{\circ} \mathrm{C} / \mathrm{min}$ (hold for $10 \mathrm{~min}$ ). The injection operating conditions were as follows $1-\mu \mathrm{L}$ injection volume and temperature of $250^{\circ} \mathrm{C}$. Helium (Air Liquide, Paris la Défense, France) at a purity of $99.99 \%$ was used as the carrier gas, with a flow rate of $1 \mathrm{~mL} / \mathrm{min}$. Electronic impact (EI) ionization mode mass spectra were obtained at $70 \mathrm{eV}$ and monitored in selective ion monitoring (SIM) mode.

Polychlorinated biphenyl detection limits (limits of quantitation, LOQ) were similar between the compounds. For PCB 28 and 52, the LOQ was $0.03 \mathrm{ng} / \mathrm{g}$ of fat; for I-PCB 101, 118, 138, 153, and 180, the LOQ was about $0.2 \mathrm{ng} / \mathrm{g}$ of fat. Recovery of I-PCB in all the samples ranged from 50 to $100 \%$.

\section{Calculations and Statistical Analysis}

The contribution of ingested matrices other than spiked feeds on PCB delivery was also investigated. Based on a feeding regimen of 2,000 g per day of uncontaminated concentrate, recorded data of contaminated feed, and approximately 1,000 g of hay per day, the contribution of the different feeds to PCB exposure was calculated. Water and air contamination were not taken into account because inhalation and drinking water are known to be of negligible importance in PCB exposure (Sweetman et al., 2000).

The amount of I-PCB ingested by each goat during each 32-d exposure period was calculated from the measured I-PCB concentration in experimental feed and the recorded amount of feed ingested. The amount of I-PCB excreted daily via milk was calculated as the concentration of I-PCB in milk, the amount of milk excreted, and the amount of milk fat.

Bioavailability of I-PCB present in soil relative to I$\mathrm{PCB}$ present in oil was estimated by means of the slope- ratio method from the I-PCB concentration in milk in response to I-PCB ingested over each 32 -d period. The method involves a one-way analysis of covariance. First, 2 assumptions were sequentially tested to validate the model. The response of I-PCB concentration in milk (ng/g of fat) to ingested I-PCB (ng/g of feed) had to be linear for each matrix (oil and soil) and the intercepts for the 2 lines needed to be equal. These assumptions being checked, the regression of I-PCB concentration in milk on the amount of I-PCB ingested was fitted for each of the 2 matrices. The RB of soil-bound I-PCB was calculated as the ratio of the slope of the response fitted with soil to the slope of the response fitted with oil (Table 2).

All the data were analyzed with SAS statistical software (SAS Institute Inc., Cary, NC), using the goat as experimental unit. To account for the correlation between milk samples successively collected from the same goat, data were analyzed by means of PROC MIXED using the repeated statement. Differences were considered significant at $P<0.05$.

In addition to the dietary concentration of $\mathrm{PCB}$ (ng/g of feed), the model included the matrix (soil or oil) to test that the 2 lines had a common intercept, the interaction between the matrix and the dietary concentration of PCB to test whether the 2 slopes were different, and the interaction between the matrix and the square of the dietary concentration of PCB to test whether the response within each matrix was linear or not:

$$
\begin{gathered}
Y_{i j}=a+M_{i j}+b \times D_{i j}+c \times \text { Milk }_{i j}+d \times \text { Weight }_{i} \\
+e \times D_{i j} \times D_{i j}+f \times M_{i j} \times D_{i j}+g \times M_{i j} \times D_{i j} \times D_{i j},
\end{gathered}
$$

where $Y_{i j}=$ the concentration of I-PCB in milk fat (ng/g of fat) for goat $i$ and matrix $j, M_{i j}=$ effect of 
matrix $j(j=1$ or 2$)$ given to goat $i, D_{i j}=\mathrm{I}-\mathrm{PCB}$ daily ingested by goat $i$ through in matrix $j$ (ng/g of feed), Milk $_{i j}=$ milk quantities excreted by goat $i$ with matrix $j$, Weight ${ }_{i}=$ weight of goat $i$ receiving matrix $j$, a $=$ the intercept, and $b, c, d, e, f$, and $g=$ the estimated parameters.

\section{RESULTS AND DISCUSSION}

Mean daily milk production was similar between treatments and for the different experimental periods. For soil feed-treated animals, the mean daily milk production was $3,941 \pm 510,3,721 \pm 523$, and $3,234 \pm$ $695 \mathrm{~g} / \mathrm{d}$ for periods 1, 2, and 3, respectively. For oil feed-treated animals, the mean daily milk production was $3,790 \pm 629,3,543 \pm 673$, and $3,328 \pm 743 \mathrm{~g} / \mathrm{d}$ for periods 1,2 , and 3 , respectively. No significant differences were noted between treatments and periods.

The PCB concentrations in the contaminated feeds are given in Table 1. Increasing concentrations were found, respectively, for soil feeds 1, 2, and 3 and for oil feeds 4, 5, and 6. Both contaminated matrices (soil and oil) were mixed directly in feed to improve the homogeneous distribution of the matrix in feed and to avoid the underestimation of the absorption of the compounds in the gastrointestinal tract due to inadequate mixing in the feed bolus ( $\mathrm{Pu}$ et al., 2006).

The concentrations of I-PCB in contaminated oil feeds were slightly lower than those reported in the contaminated soil feeds. They ranged from 16.8 and 40.3 $\mathrm{ng} / \mathrm{g}$ with soil feeds and from 9.9 and $26.3 \mathrm{ng} / \mathrm{g}$ with oil feeds. Thus, soil feeds were by 1.5 to 1.7 more concentrated in I-PCBs than oil feeds. The I-PCB profiles in oil and in soil feeds were similar, with a predominance of the more chlorinated I-PCB. The contribution of PCB 138, 153, and 180 to the sum of I-PCB reached 80 and $78 \%$ in the oil- and soil-contaminated feeds, respectively. The I-PCB profile in milk presents some similarities from that found in feed. Indeed, the contribution of PCB 138, 153, and 180 congeners reached at least $77 \%$ in milk. Polychlorinated biphenyl 153 was the major congener in milk, accounting for more than $31 \%$ of total I-PCB. This was followed by PCB 138 and 180, with 17 and $26 \%$ of total PCB levels, respectively.

Hay and uncontaminated concentrate contained 1.5 and $0.17 \mathrm{ng}$ of I-PCB $/ \mathrm{g}$, respectively. Thus, via these 2 feeds, the goats ingested daily 1.5 and $0.34 \mathrm{ng}$ of I$\mathrm{PCB}$, respectively. This result means that at least $80 \%$ of the daily exposure to PCB was achieved by ingestion of the contaminated feeds.

The recovery rates from oil feeds to milk ranged from 2.3 to $73.3 \%$ and between 1.2 to $44.2 \%$ from soil feeds to milk. The recovery rates of PCB 118 and 138 from oil feed to milk were the highest (around $73 \%$ ), followed by $\mathrm{PCB} 28,153$, and 180 in milk (around 55\%), and finally PCB 52 and $101(<5 \%)$. These differences may be due to the physical and chemical characteristics of the compounds. Indeed, the compounds are commonly classed in 3 groups (based on the stereochemical properties, such as presence of vicinal hydrogen in parameta position; Thomas et al., 1999). For example, PCB 52 and PCB 101, which belong to the third group, are known to be readily cleared.

Responses of I-PCB concentrations in milk to ingested I-PCB are presented in Figure 1. Models were fitted with coefficients of determination $\left(\mathrm{R}^{2}\right)$ ranging from 0.80 to 0.94 , except for PCB 52 and 101 (Table 2 ). For PCB 52 and 101, models fitted the data with coefficients of determination of 0.11 and 0.40 (Table 2 ). These lower parameters can be associated with the fact that these compounds are known to be readily cleared (Thomas et al., 1999) and low concentrations were detected in milk samples. For these 2 compounds, the estimated intercept exceeded zero $(P<0.01$ and $P$ $<0.001$, respectively). For PCB 52, the dose-response relationship was revealed to be nonlinear. Thus, no RB could be calculated. For PCB 101, the slopes of the 2 lines could not be differentiated $(P>0.1)$.

For the other compounds, fitted models were obtained with high coefficients of determination. The 2 relevant hypotheses for the comparison of the slopes were checked and found to be adequate: the response of the ingested I-PCB from each of the 2 matrices was linear (quadratic effect, $P>0.1$ ), and the intercepts adjusted for the 2 lines were equal (matrix, $P>0.10$ ). Moreover, the intercept did not differ from zero $(P>$ 0.1 ). For PCB 28, no significant interaction between the matrix and the dose (Table 2) was seen, suggesting that the lines of soil and oil matrices could not be statistically distinguished (Figure 1). For the remaining compounds (PCB 118, 138, 153, 180, and I-PCB), the covariance analysis (Table 2) showed significant interaction between the matrix and the dose $(P<0.001)$, which triggers the difference between the slopes of the regression lines. Relative bioavailability was calculated and varied from 36 to $50 \%$ for PCB 118, 138, and 153 and was found to be $73 \%$ for PCB 180 . When considered globally, the response obtained with the I-PCB was estimated to $51 \%$.

The RB values of most lipophilic PCB (118, 138, 153 , and 180) and the sum of I-PCB suggest that soil (0.71\% organic carbon and $6.3 \%$ clay) reduces, to a limited extent, their bioavailability compared with the oil matrix. Recently, Fournier et al. (2012) observed that the same soil as the one used in the current study did not significantly modulate I-PCB availability in laying hens. Therefore, the difference in the soil effect on I-PCB availability seems to be related to the animal 

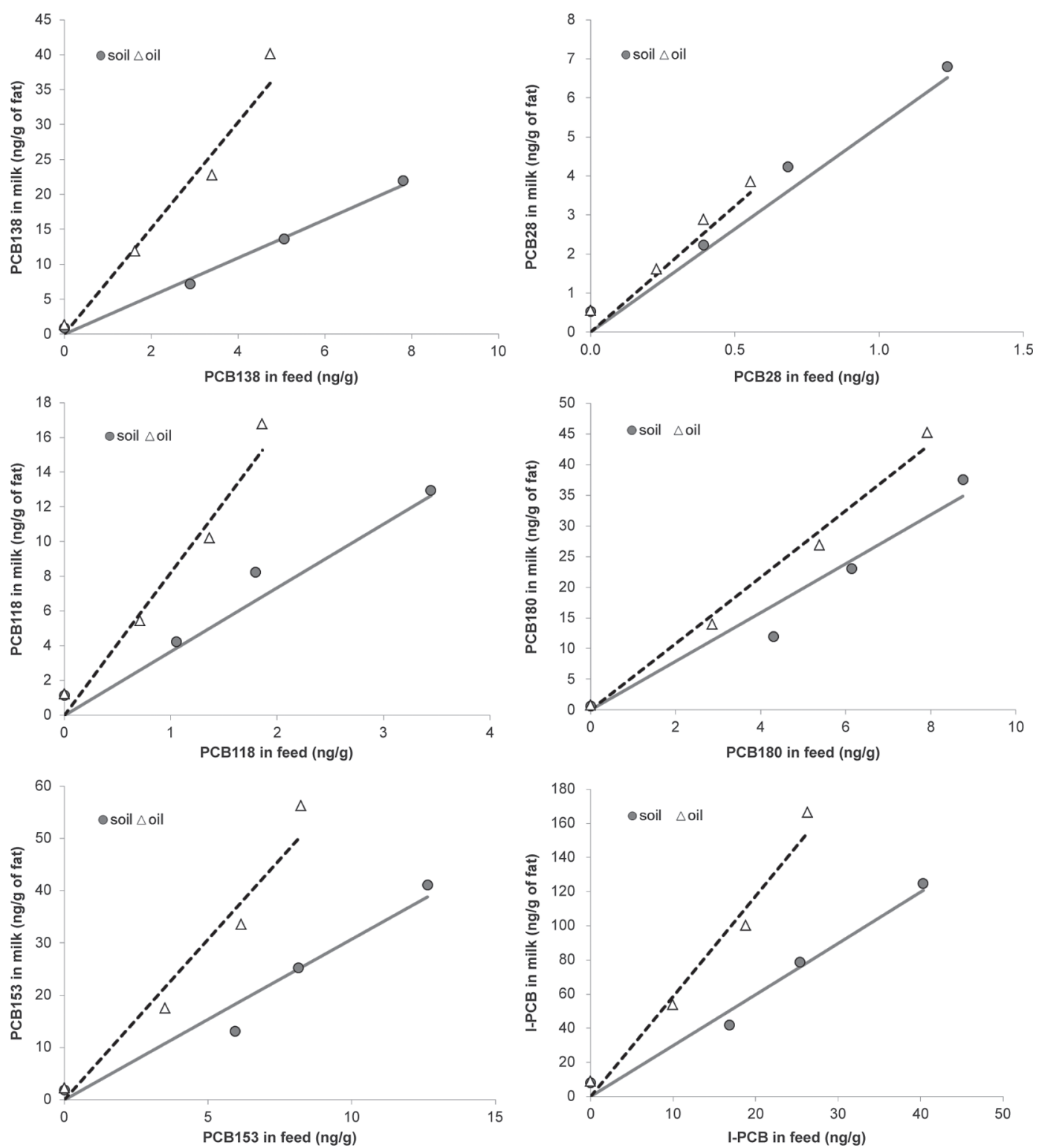

Figure 1. Dose-response relationship between concentrations excreted in milk (ng/g fat) and concentrations ingested (ng/g feed) of some individual and total indicator polychlorinated biphenyls (I-PCB). Values are means of concentrations in the milk $(\mathrm{n}=4)$.

species. Specific differences in digestive characteristics such as retention time, bile secretion, and subsequent mixed micelle formation may explain the higher capacity of hens to extract PCB from ingested soil.

The reduced RB in goats observed in this study is in line with the results of Slob et al. (1995) who showed a significant reduction $(65 \%)$ of the bioavailability of PCB in cow milk after dust particle (fly ash) administration. Hoogenboom et al. (2006) also reported an effect of soil on PCB bioavailability in eggs (BR from 45 to $65 \%$ ). Fries et al. (1989) showed in rats a limited, but significant, reduction (10 to $20 \%$ for $3 \mathrm{PCB}$ ) of oral bioavailability of $\mathrm{PCB}$ when bound to soil $(5 \%$
OM; $10 \%$ clay). Similar conclusions were reported in in vitro investigations mimicking the monogastric digestive tract. A reduction in the PCB mobilized fraction of $67 \%$ was found (Hack and Selenka, 1996).

The reduction of the bioavailability of PCB 118, 138, 153,180 , and I-PCB in the current study could also be related to the fact that the origin of the contamination was a fire that occurred at the soil level. Thus, the studied soil could have been contaminated by fly ashes, known for their specific retention toward the organic compounds such as PCB. Indeed, combustion residues (e.g., soot and ashes) are specific organic carbons that are recognized for their low solubility and their encap- 
sulation of hydrophobic organic chemicals (Grøn et al., 2007). On the contrary, the soil constituents appeared not to influence the bioavailability of PCB 28 and 101, as suggested by $\mathrm{Pu}$ et al. (2006). Those authors did not observe any availability reduction of PCB 52 and 101 in rats given 5 soils differing in their organic carbon and clay contents ( 0.52 to $2.9 \%$ and 8 to $38 \%$, respectively) compared with oil.

However, although the RB of soil-bound PCB was reduced by about $50 \%$, it is relevant to keep in mind that a significant amount of soil-bound PCB was released from the soil matrix during the digestive process of the ruminant. Therefore, contaminated soil has to be considered as a risk matrix for ruminant. Therefore, in accidentally contaminated areas, it appears necessary to select feeding practices and fodder crop with the aim to limit involuntary ingestion of soil. Indeed, Figure 1 clearly indicates that the threshold level of $40 \mathrm{ng} / \mathrm{g}$ of fat (Regulation 1259/2011/UE) was exceeded for each experimental feed and for each studied level.

\section{CONCLUSIONS}

This study aimed to evaluate the relative bioavailability of soil bound PCB in lactating ruminants. Overall RB was $51 \%$ for the sum of I-PCB. This result has 2 main implications. First, soil elements contribute to reduce, to a limited extent, the bioavailability of $\mathrm{PCB}$ from soil. It would now be of interest to better characterize these effects, all the more because the current results were obtained in a given contaminated area and involved only one kind of soil. Thus, further research work needs to be carried out with different kinds of soils and pollutants to establish general rules on soilbound pollutant bioavailability. Second, a significant portion of soil-bound PCB appears to be bioavailable and contributes to the exposure of the target species. This result is sufficiently clear to warrant consideration when assessing risk associated with environmental contamination. Thus, contaminated soil has to be considered as a potential contributor to lactating ruminant contamination by I-PCB. All feeding practices that contribute to involuntary soil ingestion should be avoided in contaminated areas.

\section{ACKNOWLEDGMENTS}

The authors are grateful to the French National Institute of Agricultural Research (Division of Animal Physiology and Livestock Systems, Paris, France) for financial support. They thank K. Tack [Institut National de l'Environnement Industriel et des Risques (INERIS), Verneuil-en-Halatte, France] for providing contaminated soil, N. Besnes and M. Gibelin [INRA,
Pôle Expérimental Avicole de Tours (PEAT), Nouzilly, France] for experimental feed manufacturing, and P. Hartmeyer [INRA, Unité de recherche animal et fonctionnalités des produits animaux (UR AFPA), Vandœuvre-lès-Nancy, France] for care of the goats.

\section{REFERENCES}

Costera, A., C. Feidt, P. Marchand, B. Le Bizec, and G. Rychen. 2006 PCDD/F and PCB transfer to milk in goats exposed to a longterm intake of contaminated hay. Chemosphere 64:650-657.

Darnerud, P. O., S. Atuma, M. Aune, R. Bjerselius, A. Glynn, K. P Grawé, and W. Becker. 2006. Dietary intake estimations of organohalogen contaminants (dioxins, PCB, PBDE and chlorinated pesticides, e.g. DDT) based on Swedish market basket data. Food Chem. Toxicol. 44:1597-1606.

Focant, J.-F., G. Eppe, C. Pirard, A.-C. Massart, J.-E. André, and E. De Pauw. 2002. Levels and congener distributions of PCDDs, PCDFs and non-ortho PCBs in Belgian foodstuffs: Assessment of dietary intake. Chemosphere 48:167-179.

Fournier, A., C. Feidt, A. Travel, B. Le Bizec, A. Venisseau, P. Marchand, and C. Jondreville. 2012. Relative bioavailability to laying hens of indicator polychlorobiphenyls present in soil. Chemosphere 88:300-306.

Fries, G. F. 1995. A review of the significance of animal food products as potential pathways of human exposures to dioxins. J. Anim. Sci. 73:1639-1650.

Fries, G. F., G. S. Marrow, and C. J. Somich. 1989. Oral bioavailability of aged polychlorinated biphenyl residues contained in soil. Bull. Environ. Contam. Toxicol. 43:683-690.

Grøn, C., A. Oomen, E. Weyand, and J. Wittsiepe. 2007. Bioaccessibility of PAH from Danish soils. J. Environ. Sci. Health A Tox. Hazard Subst. Environ. Eng. 42:1233-1239.

Hack, A., and F. Selenka. 1996. Mobilization of PAH and PCB from contaminated soil using a digestive tract model. Toxicol. Lett. $88: 199-210$.

Hoogenboom, L. A. P., C. A. Kan, M. J. Zeilmaker, J. Van Eijkeren, and W. A. Traag. 2006. Carry-over of dioxins and PCBs from feed and soil to eggs at low contamination levels-Influence of mycotoxin binders on the carry-over from feed to eggs. Food Addit. Contam. 23:518-527.

INRA (Institut National de la Recherche Agronomique). 2007. Alimentation des bovins, ovins et caprins: Besoins des animaux-Valeurs des aliments: Tables Inra 2007. Éditions Quæ, Versailles, France.

Jurjanz, S., C. Feidt, L. A. Pérez-Prieto, H. M. N. Ribeiro Filho, G. Rychen, and R. Delagarde. 2012. Soil intake of lactating dairy cows in intensive strip grazing systems. Animal 6:1350-1359.

Kawamaru, Y., E. Kamata, Y. Ogawa, T. Kaneko, S. Uchiyama, and Y. Saito. 1988. The effect of various foods on the intestinal absorption of benzo $(a)$ pyrene in rats. Shokuhin Eiseigaku Zasshi $29: 21-25$.

Kookana, R. S. 2011. Fate of persistent organic pollutants (Pops) in soils and their effect on food safety. CSIRO land and water. Accessed Sep. 4, 2012. http://www.agnet.org/library.php?func=view \&id=20110804154803\&type_id=4.

Mamontova, E. A., E. N. Tarasova, A. A. Mamontov, M. I. Kuzmin, M. S. McLachlan, and M. I. Khomutova. 2007. The influence of soil contamination on the concentrations of PCBs in milk in Siberia. Chemosphere 67:S71-S78.

Matscheko, N., M. Tysklind, C. de Wit, S. Bergek, R. Andersson, and U. Sellström. 2002. Application of sewage sludge to arable land-soil concentrations of polybrominated diphenyl ethers and polychorinated dibenzo- $p$-dioxins, dibenzofurans, and biphenyls, and their accumulation in earthworms. Environ. Toxicol. Chem. 21:2515-2525.

McLachlan, M. S., H. Thoma, M. Reissinger, and O. Hutzinger. 1990. $\mathrm{PCDD} / \mathrm{F}$ in an agricultural food chain. Part 1: PCDD/F mass balance of a lactating cow. Chemosphere 20:1013-1020.

Ounnas, F., C. Feidt, H. Toussaint, G. Rychen, P. Marchand, B. Le Bizec, G. Rychen, and S. Jurjanz. 2010. Polychlorinated biphenyl 
and low polybrominated diphenyl ether transfer to milk in lactating goats chronically exposed to contaminated soil. Environ. Sci. Technol. 44:2682-2688.

Ounnas, F., S. Jurjanz, M. A. Dziurla, Y. Guiavarc'h, C. Feidt, and G. Rychen. 2009. Relative bioavailability of soil-bound polycyclic aromatic hydrocarbons in goats. Chemosphere 77:115-122.

Pu, X., L. S. Lee, R. E. Galinsky, and G. P. Carlson. 2006. Bioavailability of 2,3',4,4',5-pentachlorobiphenyl (PCB118) and 2,2',5,5'-tetrachlorobiphenyl (PCB52) from soils using a rat model and a physiologically based extraction test. Toxicology 217:14-21.

Rychen, G., S. Jurjanz, H. Toussaint, and C. Feidt. 2008. Dairy ruminant exposure to persistent organic pollutants and excretion to milk. Animal 2:312-323.
Slob, W., M. Olling, H. J. G. M. Derks, and A. P. J. M. de Jong. 1995. Congener-specific bioavailability of PCDD/Fs and coplanar PCBs in cows: Laboratory and field measurements. Chemosphere 31:3827-3838

Sweetman, A. J., R. E. Alcock, J. Wittsiepe, and K. C. Jones. 2000. Human exposure to PCDD/FS in the UK: The development of a modelling approach to give historical and future perspectives. Environ. Int. 26:37-47.

Thomas, G. O., A. J. Sweetman, and K. C. Jones. 1999. Metabolism and body-burden of PCBs in lactating dairy cows. Chemosphere 39:1533-1544. 